\title{
LA LEGISLACIÓN BÁSICA DE PROTECCIÓN DEL MEDIO AMBIENTE (SEGUNDO SEMESTRE 2018)
}

\author{
LAURA PRESICCE \\ Investigadora Predoctoral Contratada FI \\ Departamento de Derecho Público - Universitat Rovira i Virgili
}


Sumario: 1. Introducción. 2. El cambio de Gobierno y la reestructuración organizativa: el nuevo Ministerio para la Transición Ecológica y la Comisión Interministerial para el Cambio Climático y la Transición Ecológica. 3. Novedades normativas en ámbitos sectoriales. 3.1. En materia de patrimonio natural y biodiversidad, medio marino y espacios naturales protegidos. 3.2. En materia de envases de plástico. 3.3. En materia de subproductos y suelos contaminados. 3.4 En materia de contaminación atmosférica. 3.5. En materia de hidrocarburos y gas natural. 3.6. En materia de sector eléctrico. 4. Otras normas de interés.

\section{INTRODUCCIÓN}

Continuando en la misma línea trazada en los primeros meses del año, durante el periodo objeto de análisis (1 de abril 2018 - 30 de septiembre de 2018), a nivel estatal se ha registrado una actividad normativa en materia ambiental poco significativa. Destacamos únicamente una norma con rango de Ley (la Ley $7 / 2018$, de 20 de julio, de modificación de la Ley 42/2007, de 13 de diciembre, del Patrimonio Natural y de la Biodiversidad), aunque se limita a modificar aspectos puntales de una Ley ya existente. Las demás normas aprobadas son de rango reglamentario y, excepto casos puntales (por ejemplo, el Real Decreto 699/2018, de 29 de junio, por el que se declara Área Marina Protegida el Corredor de migración de cetáceos del Mediterráneo), no contienen novedades de gran calado, sino que se limitan a aportar modificaciones a la normativa existente $\mathrm{o}$ a incorporar en el ordenamiento jurídico español directivas europeas.

Antes de entrar a reseñar las novedades legislativas estatales en los diferentes sectores, es imprescindible destacar un acontecimiento muy importante al que no podemos dejar de hacer referencia: el pasado día 1 de junio, Pedro Sánchez, líder del PSOE, se ha convertido en el séptimo presidente del Gobierno de España ${ }^{1}$ tras prosperar, por primera vez desde la vuelta a la democracia en 1977, la moción de censura contra Mariano Rajoy. La moción de censura, registrada por el Grupo Socialista tras conocerse la sentencia confirmatoria del caso Gürtel, ha salido adelante también gracias al apoyo de PNV, ERC y PDeCAT. Después de la publicación del nombramiento, el nuevo Presidente ha modificado la estructura básica de los departamentos

\footnotetext{
${ }^{1}$ Vid. Real Decreto 354/2018, de 1 de junio, por el que se nombra Presidente del Gobierno a don Pedro Sánchez Pérez-Castejón, BOE núm. 134, de 2 de junio de 2018.
} 
ministeriales existente ${ }^{2} y$, en concreto, para lo que concierne al medio ambiente, desaparecen el Ministerio de Agricultura y Pesca, Alimentación y Medio Ambiente así como el Ministerio de Energía, Turismo y Agenda Digital y se crean dos nuevos ministerios: el Ministerio de Agricultura, Pesca y Alimentación, cuyo objetivo es la propuesta y ejecución de la política del Gobierno en materia de recursos agrícolas, ganaderos y pesqueros, de industria agroalimentaria, de desarrollo rural y de alimentación; y el Ministerio para la Transición Ecológica que se ocupará, como veremos en el apartado siguiente, de la propuesta y ejecución de la política del Gobierno en materia de energía y medio ambiente para la transición a un modelo productivo y social más ecológico. La novedosa distribución competencial para los nuevos Ministerios responde a la más adecuada expresión de los objetivos prioritarios del Gobierno y de su programa político en aras a lograr mayor eficacia en su acción y mayor eficiencia en el funcionamiento de la Administración General del Estado.

Asimismo, ha nombrado a Luis Plana Puchades como Ministro de Agricultura, Pesca y Alimentación a y Teresa Ribera Rodríguez como Ministra para la Transición Ecológica. La nueva Ministra se ha comprometido desde su nombramiento a presentar al Congreso de Diputados una nueva Ley de Cambio Climático antes de final de año. En concreto, la Ministra estaría trabajando para mejorar y adaptar el borrador de la Ley de Cambio Climático dejado por la anterior Ministra de Agricultura y Pesca, Alimentación y Medio Ambiente, Isabel García Tejerina.

\section{EL CAMBIO DE GOBIERNO Y LA REESTRUCTURACIÓN} ORGANIZATIVA: EL NUEVO MINISTERIO PARA LA TRANSICIÓN ECOLÓGICA Y LA COMISIÓN INTERMINISTERIAL PARA EL CAMBIO CLIMÁTICO Y LA TRANSICIÓN ECOLÓGICA

Desde un punto de vista organizativo, como se ha señalado anteriormente, el cambio de Gobierno ha producido la reestructuración de los departamentos ministeriales $y$, en concreto, por lo que concierne al nuevo Ministerio para la

\footnotetext{
${ }^{2}$ Vid. Real Decreto 355/2018, de 6 de junio, por el que se reestructuran los departamentos ministeriales, BOE núm. 138, de 7 de junio de 2018.
} 
Transición Ecológica, destacamos el Real Decreto 864/2018, de 13 de julio, por el que se desarrolla la estructura orgánica básica del Ministerio para la Transición Ecológica ${ }^{3}$.

El Ministerio para la Transición Ecológica, establecido por el Real Decreto $355 / 2018$, de 6 de junio, por el que se reestructuran los departamentos ministeriales, y el Real Decreto 595/2018, de 22 de junio, por el que se establece la estructura orgánica básica de los departamentos ministeriales, es el departamento de la Administración General del Estado al que corresponde la propuesta y ejecución de la política del Gobierno en materia de energía y medio ambiente para la transición a un modelo productivo y social más ecológico.

En el ámbito de las competencias del Estado, el Ministerio para la Transición Ecológica tiene competencias en la elaboración de la legislación estatal en materia de aguas y costas, medio ambiente, meteorología y climatología; de gestión directa del dominio público hidráulico, del dominio público marítimoterrestre (protección y conservación del mar y del dominio público marítimoterrestre, así como la participación en la planificación de la política de investigación en materia de biodiversidad de los ecosistemas marinos). Asimismo, corresponde al Ministerio para la Transición Ecológica el desarrollo de la política energética y minera nacional, junto con las medidas destinadas a asegurar el abastecimiento energético y la coordinación de la proyección exterior en la materia, garantizando una correcta regulación del sector y el análisis y seguimiento de estos mercados, junto con las competencias en minería, todo ello en el marco de la transición ecológica.

En materia energética, el Ministerio persigue potenciar las capacidades de análisis y evaluación de los sectores energéticos, a efectos de elaborar las regulaciones sectoriales más adecuadas y, en esto, buscará combinar una doble aproximación: por una parte, una metodología rigurosa de identificación y eliminación de las ineficiencias que limitan en el corto plazo la actividad económica; por otra, una actuación continuada de reforma y mejora de los sectores competencia del Ministerio, dirigida especialmente a promover una

\footnotetext{
${ }^{3}$ Vid. BOE núm. 170, de 14 de julio de 2018.
} 
transición energética ordenada, así como el desarrollo y uso seguro de redes de nueva generación. El Ministerio se estructura en dos órganos superiores: la Secretaría de Estado de Energía y la Secretaría de Estado de Medio Ambiente.

Además del citado Ministerio, a través del Real Decreto 958/2018, de 27 de julio $^{4}$, se crea y regula la Comisión Interministerial para el Cambio Climático y la Transición Energética. La política del Gobierno en materia de transición ecológica se dirige a reforzar y promover la atención de los asuntos relacionados con la lucha contra el cambio climático y con la transición energética, lo que, unido a la relevancia económica, ambiental y social de esta materia, justifica la modificación de la actual Comisión Interministerial para el Cambio Climático, adecuándola al impulso en la materia, modificando su denominación y ajustándola a la nueva planta departamental. La Comisión Interministerial para el Cambio Climático y la Transición Energética, adscrita al Ministerio para la Transición Ecológica, se crea con el fin de lograr el mejor tratamiento de las políticas públicas en esta materia, desde una perspectiva participativa y multidisciplinar, y se le asigna una amplia variedad de funciones de impulso y coordinación y, entre otras, impulsar y coordinar las actuaciones de los órganos concernidos de la Administración General del Estado, para la elaboración del Anteproyecto de Ley de cambio climático y transición energética, del Plan Nacional Integrado de Energía y Clima o de la estrategia para la descarbonización de la economía a 2050.

Asimismo, a través del Real Decreto 904/2018, de 20 de julio ${ }^{5}$, se desarrolla la estructura orgánica básica del Ministerio de Agricultura, Pesca y Alimentación, y se modifica el Real Decreto 595/2018, de 22 de junio, por el que se establece la estructura orgánica básica de los departamentos ministeriales. Al Ministerio compete la propuesta y ejecución de la acción del Gobierno en materia de producción primaria y mercados agrarios, sanidad de la producción agraria, industria alimentaria y desarrollo rural, innovación sectorial y del territorio rural y política forestal; la planificación y ejecución de las políticas en materia de pesca marítima en aguas exteriores y acuicultura, ordenación básica del sector pesquero, bases de la comercialización y transformación de los productos

\footnotetext{
${ }^{4}$ Vid. BOE núm. 182, de 28 de julio de 2018.

${ }^{5}$ Vid. BOE núm. 176 de 21 de julio de 2018.
} 
pesqueros y participación en la planificación de la política de investigación en materia de pesca.

\section{NOVEDADES NORMATIVAS EN ÁMBITOS SECTORIALES}

En el período objeto de este análisis (1 de abril - 30 de septiembre 2018) han sido aprobadas numerosas normas de rango reglamentario en materia ambiental, en diferentes ámbitos sectoriales. Entre ellas, nos limitamos a destacar las más significativas.

\subsection{En las materias de patrimonio natural y biodiversidad, medio marino y espacios naturales protegidos}

En cuanto a la legislación ambiental, en materia de biodiversidad cabe, sin duda, destacar la Ley 7/2018, de 20 de julio, de modificación de la Ley 42/2007, de 13 de diciembre, del Patrimonio Natural y de la Biodiversidad ${ }^{6}$. A través de la modificación de la Ley 42/2007, de 13 de diciembre, del Patrimonio Natural y de la Biodiversidad (contenida en la Ley 7/2018, de 20 de julio), se pretende compatibilizar la imprescindible lucha contra las especies exóticas invasoras con su aprovechamiento para la caza y la pesca en aquellas áreas que, al estar ocupadas desde antiguo, su presencia no suponga un problema ambiental. La Ley objeto de análisis pretende encontrar una solución que compatibilice la protección del medio ambiente, de conformidad con la sentencia del Tribunal Supremo n. ${ }^{\circ}$ 637/2016, de 16 de marzo, con la actividad y el empleo de los sectores cinegético y piscícola, teniendo en cuenta lo dispuesto en el Reglamento 1143/2014, de 22 de octubre, del Parlamento Europeo y del Consejo. La STS n. ${ }^{\circ}$ 637/2016, de 16 de marzo, al modificar la lista de especies catalogadas y anular varias disposiciones del Real Decreto 630/2013, por el que se regula el Catálogo español de especies exóticas invasoras, generó una gran preocupación por sus efectos económicos y sociales ya que, además de implicar la prohibición genérica de posesión, transporte, tráfico y comercio de ejemplares vivos de varias especies que son objeto de aprovechamiento piscícola o cinegético, supuso la imposibilidad de la práctica de la caza y la pesca deportivas de las especies catalogadas, salvo en

\footnotetext{
${ }^{6}$ Vid. BOE núm. 176 de 21 de julio de 2018.
} 
el marco de las campañas de control y erradicación. La Ley a que venimos haciendo referencia, que ha entrado en vigor el 22 de julio de 2018, además de incorporar una definición de los recursos zoogenéticos, que no había tenido cabida en la anterior legislación, dispone que se seguirá considerando que las especies exóticas invasoras para las que exista suficiente información científica deberán ser catalogadas, pero se permitirá que, en aquellas áreas ocupadas antes de 2007, se podrán utilizar todas las modalidades de caza y pesca para su control o erradicación. Por el contrario, fuera de esas áreas queda prohibido el aprovechamiento de pesca o caza deportivas. Además, establece normas específicas para regular la acuicultura y habilita un mecanismo excepcional para que la Comisión Estatal de Patrimonio Natural y la Biodiversidad pueda acordar, en casos excepcionales y en los supuestos con regulación específica, la suspensión del procedimiento de catalogación de una especie o promover la descatalogación de una especie previamente catalogada.

Respecto al medio marino, muy interesante resulta la aprobación por el Consejo de Ministros, a propuesta del Ministerio para la Transición Ecológica, del Real Decreto 699/2018, de 29 de junio, por el que se declara Área Marina Protegida el Corredor de migración de cetáceos del Mediterráneo, se aprueba un régimen de protección preventiva y se propone su inclusión en la Lista de Zonas Especialmente Protegidas de Importancia para el Mediterráneo (Lista ZEPIM) en el marco del Convenio de Barcelona ${ }^{7}$. En 2004, el "Proyecto Mediterráneo para la identificación de las Áreas de Especies de interés para la Conservación de los Cetáceos en el Mediterráneo Español" identificó este espacio, ubicado entre las costas de Alicante, Gerona y las Islas Baleares ${ }^{8}$, como un área de especial interés y remarcó la necesidad de proteger la zona por ser una ruta migratoria y concentrar gran diversidad de especies de cetáceos. Para ello, proponía la declaración de este espacio como Zona Especialmente Protegida de Importancia para el Mediterráneo (ZEPIM) del

\footnotetext{
${ }^{7}$ Vid. BOE núm. 178, de 30 de junio de 2018.

8 "Esta área se extiende por el norte dentro de las aguas de soberanía española a la altura del Cabo de Creus, en Gerona, hasta el Cabo de la Nao, en Alicante, por el sur; por el este, discurre paralela a las costas de islas de Ibiza, Mallorca y Menorca, a una distancia de unos $13 \mathrm{~km}$; y por el oeste, también paralela a las costas catalana y valenciana, se mantiene a unos $38 \mathrm{~km}$ de distancia media. El espacio marino, incluidas las aguas en las que está integrado, el fondo y la columna de aire suprayacente, constituyen un ecosistema de gran importancia y muy vulnerable, donde existen especies de gran valor". Vid. Preámbulo del citado Real Decreto.
} 
Convenio de Barcelona. El objetivo de este Real Decreto es, por tanto, dotar de una figura nacional de protección a este espacio de Corredor de Migración de Cetáceos, así como su propuesta de inclusión en la Lista de Zonas Especialmente Protegidas de Importancia para el Mediterráneo (ZEPIM). Además, pretende instaurar un régimen de protección preventiva ante aquellas actividades que pudieran poner en riesgo sus valores naturales. Las medidas previstas están recogidas en el artículo 2 del citado Real Decreto y, en concreto, "no se permitirá el uso de sistemas activos destinados a la investigación geológica subterránea, tanto por medio de sondas, aire comprimido o explosiones controladas como por medio de perforación subterránea, en el área comprendida en el artículo 1, salvo aquéllas relacionadas con permisos de investigación o explotación en vigor. Quedará prohibido cualquier tipo de actividad extractiva de hidrocarburos, salvo aquéllas relacionadas con permisos de investigación o explotación en vigor".

En cuanto a la protección del medio marino, resaltamos el Real Decreto 957/2018, de 27 de julio, por el que se modifica el anexo I de la Ley 41/2010, de 29 de diciembre, de protección del medio marino ${ }^{9}$. El Real Decreto cumple con el objetivo de modificar el anexo I de la Ley 41/2010, de 29 de diciembre, para adaptarlo al nuevo texto del anexo III de la Directiva 2008/56/CE de 17 de junio de 2008, Directiva Marco sobre la estrategia marino, que proviene de la Directiva (UE) 2017/845, de la Comisión de 17 de mayo de 2017.

Asimismo, en materia de espacios naturales protegidos, en abril, fue aprobado el Real Decreto 190/2018, de 6 de abril, por el que se declara Zona Especial de Conservación el Lugar de Importancia Comunitaria LIC ES6300001 Islas Chafarinas de la región biogeográfica mediterránea de la Red Natura 2000, se amplía y se hace coincidir con el anterior espacio la Zona de Especial Protección para las Aves de igual nombre, y se aprueban las correspondientes medidas de conservación del espacio conjunto ${ }^{10}$. El objetivo del citado Real Decreto es asegurar la conservación de la integridad de los ecosistemas presentes en el archipiélago, que constituye el hogar de grandes colonias de

\footnotetext{
${ }^{9}$ Vid. BOE núm. 213, de 3 de septiembre de 2018.

${ }^{10}$ Vid. BOE núm. 97, de 21 de abril de 2018.
} 
gaviotas y otras aves que anidan en sus acantilados de difícil acceso y fuerte erosión.

\subsection{En materia de envases de plástico}

Importantes novedades para la lucha contra la dispersión de los residuos plásticos en el medio ambiente han sido introducidas por el Real Decreto 293/2018, de 18 de mayo, sobre reducción del consumo de bolsas de plástico y por el que se crea el Registro de Productores ${ }^{11}$ y que incorpora al ordenamiento jurídico español la Directiva (UE) 2015/720 del Parlamento Europeo y del Consejo, de 29 de abril de 2015, por la que se modifica la Directiva 94/62/CE en lo que se refiere a la reducción del consumo de bolsas de plástico ligeras ${ }^{12}$. Las bolsas de plástico dispersas provocan contaminación en el medio ambiente y agravan el problema generalizado de la presencia de residuos en las masas de agua, lo que supone una amenaza para los ecosistemas acuáticos en el ámbito mundial. Las bolsas de plástico "ligeras", representan la inmensa mayoría del número total de bolsas de plástico consumidas en la Unión Europea y se convierten más rápidamente en residuos debido a su reducido peso. Para hacer frente al problema del consumo de bolsas de plástico ligeras, la Directiva (UE) 2015/720 del Parlamento Europeo y del Consejo, de 29 de abril de 2015, establece que los Estados miembros han de adoptar medidas con el fin de reducir de forma sostenida, en su territorio, el consumo de este tipo de bolsas. Para ello, proporciona varias opciones a los Estados miembros entre las que se incluye el establecimiento de objetivos nacionales de reducción, la introducción de instrumentos económicos, así como, en su caso, las restricciones a su comercialización, siempre que estas restricciones sean proporcionadas y no discriminatorias. Así, a través del Real Decreto en objeto, se adoptan en España las siguientes medidas ${ }^{13}$ : en primer lugar, desde el 1 de julio de 2018 se prohíbe la entrega gratuita de las bolsas de plástico ligeras a los consumidores, en los puntos de venta y, por ende, desde esa fecha los comerciantes deben cobrar un precio por cada bolsa de

\footnotetext{
${ }^{11}$ Vid. BOE núm. 122, de 19 de mayo de 2018.

${ }^{12}$ Por bolsas de plástico ligeras se entienden bolsas de plástico con un espesor de menos de 50 micras.

${ }^{13}$ Vid. art. 4 Real Decreto 293/2018, de 18 de mayo, sobre reducción del consumo de bolsas de plástico y por el que se crea el Registro de Productores.
} 
plástico ligera que entreguen al consumidor. Se exceptúan de esta medida las bolsas de plástico muy ligeras (las bolsas de plástico de menos de 15 micras de espesor) que son necesarias por razones de higiene, o que se suministran como envase primario para alimentos a granel. En segundo lugar, desde el 1 de enero de 2021 se prohíbe la entrega -gratuita o no- a los consumidores, en los puntos de venta, de bolsas de plástico ligeras y muy ligeras no compostables. Asimismo, para evitar los perjuicios sobre los suelos, las aguas y la biota derivados de la permanencia en el medio ambiente de los plásticos, pero en partículas de menor tamaño, se prohíbe también la entrega de bolsas de plástico fragmentable a partir del 1 de enero de 2020, entendiendo como tales las bolsas de plástico fabricadas con materiales plásticos que incluyen aditivos que catalizan la fragmentación del material plástico en microfragmentos. A través del Real Decreto se han adoptado medidas para las bolsas de un espesor igual o superior a las 50 micras: por una parte, se obliga al cobro de un precio por dichas bolsas desde el 1 de julio de 2018 excepto para las que tengan un porcentaje de plástico reciclado igual o superior al $70 \%$, $y$, por otra, se establece la obligación de que estas bolsas contengan, a partir del 1 de enero de 2020, un porcentaje mínimo de plástico reciclado del 50 \%, y se propone para las mismas un precio orientativo menor. Todas estas medidas afectarán también a las bolsas que puedan suministrarse en la venta online, así como a las entregadas a domicilio. El Real Decreto prevé también la realización de campañas de sensibilización por parte de las autoridades competentes con el objetivo de informar sobre el reciclaje de las bolsas de plástico y sobre los efectos nocivos que supone el abandono de los plásticos en el medio ambiente. Finalmente, el Real Decreto crea el Registro de Productores de Productos $^{14}$, registro de carácter administrativo y declarativo, adscrito a la Dirección General de Calidad y Evaluación Ambiental y Medio Natural del Ministerio de Agricultura y Pesca, Alimentación y Medio Ambiente, con la finalidad de disponer de información sobre la puesta en el mercado de bolsas de plástico.

\subsection{En materia de subproductos y suelos contaminados}

\footnotetext{
${ }^{14}$ Vid. Capítulo III del Real Decreto 293/2018, de 18 de mayo, sobre reducción del consumo de bolsas de plástico y por el que se crea el Registro de Productores.
} 
La Ley 22/2011, de 28 de julio, de residuos y suelos contaminados, traspone la Directiva 2008/98/CE del Parlamento Europeo y del Consejo, de 19 de noviembre de 2008 , sobre residuos y concreta, en su artículo 4.1 , todas las condiciones para que una sustancia u objeto, resultante de un proceso de producción, y cuya finalidad primaria no sea la producción de esa sustancia u objeto, pueda ser considerada como un subproducto y no como un residuo.

De acuerdo con el procedimiento previsto en el artículo 4.2 de la Ley 22/2011, de 28 de julio, de residuos y suelos contaminados, para la evaluación de la consideración de un residuo de producción utilizado en un uso específico como subproducto, cuando se cumplan dichas condiciones, se procederá a elaborar una orden ministerial donde se establecerán los requisitos exigibles a las empresas para gestionar como subproducto ese residuo de producción en ese uso específico.

La finalidad de la Orden APM/397/2018, de 9 de abril, por la que se determina cuándo los recortes de espuma de poliuretano utilizados en la fabricación de espuma compuesta, se consideran subproductos con arreglo a la Ley 22/2011, de 28 de julio, de residuos y suelos contaminados ${ }^{15}$, es precisamente establecer los requisitos técnicos de las espumas y las obligaciones de los productores y de los usuarios de dicho material. Los recortes de espuma de poliuretano que se destinen a la fabricación de espumas compuestas podrán declararse subproductos siempre y cuando se cumplan los requisitos establecidos en el artículo 3 de la citada orden. En caso contrario, en que dichos requisitos no se cumplieran, los residuos de producción procedentes de la fabricación de espuma de poliuretano no podrán ser destinados a la fabricación de espumas compuestas como subproducto, por lo que tendrán que gestionarse bajo el régimen jurídico de residuos, con el fin de asegurar su correcta gestión y proteger adecuadamente la salud humana y el medio ambiente.

\subsection{En materia de contaminación atmosférica}

La contaminación atmosférica representa un importante riesgo para la salud humana, el medio ambiente y demás bienes de cualquier naturaleza y, por este

${ }^{15}$ Vid. BOE núm. 95, de 19 de abril de 2018. 
motivo, la calidad del aire y la protección de la atmósfera han sido, desde hace décadas, una prioridad de la política ambiental española y europea.

El Real Decreto 818/2018, de 6 de julio, sobre medidas para la reducción de las emisiones nacionales de determinados contaminantes atmosféricos ${ }^{16}$, tiene como objetivo incorporar al ordenamiento jurídico español la llamada "Directiva de Techos", la Directiva (UE) 2016/2284 del Parlamento Europeo y del Consejo, de 14 de diciembre de 2016, que establece los compromisos de reducción de emisiones de los Estados miembros para las emisiones atmosféricas antropogénicas. La citada Directiva, que modifica la Directiva 2003/35/CE y deroga la Directiva 2001/81/CE, del Parlamento Europeo y del Consejo, de 23 de octubre, revisa el régimen de techos nacionales de emisión $y$, en concreto, establece los compromisos de reducción de emisiones de los Estados miembros para las emisiones atmosféricas antropogénicas de dióxido de azufre (SO2), óxidos de nitrógeno (NOx), compuestos orgánicos volátiles no metánicos (COVNM), amoniaco (NH3), y partículas finas (PM2,5). Prevé también la adopción, por parte de los Estados miembros, de un programa nacional de control de la contaminación atmosférica y el seguimiento de las emisiones y sus efectos en los ecosistemas, así como la presentación de información al respecto. A través del Real Decreto 818/2018, de 6 de julio, sobre medidas para la reducción de las emisiones nacionales de determinados contaminantes atmosféricos, el Gobierno de España, para cumplir los compromisos de reducción de emisiones en los horizontes temporales 2020 y 2030 establecidos por la citada Directiva, fija los objetivos de reducción de las emisiones atmosféricas antropogénicas de dióxido de azufre (SO2), óxidos de nitrógeno (NOx), compuestos orgánicos volátiles no metánicos (COVNM), amoniaco (NH3), y partículas finas (PM2,5). Concretamente, el capítulo II fija los compromisos nacionales de emisión, remitiéndose al anexo I en cuanto a la concreta enumeración de las sustancias contaminantes a las que son de aplicación estas reducciones y fijando cuantitativamente, en el anexo II, los objetivos a alcanzar para cada una de ellas en el período considerado. Asimismo, el Real Decreto regula, en el Capítulo III, la elaboración, adopción y aplicación, por parte de España, de un programa nacional de control de la

${ }^{16}$ Vid. BOE núm. 164, de 7 de julio de 2018. 
contaminación atmosférica, cuyo fin es cumplir con los compromisos de reducción de emisiones y contribuir a la consecución de los objetivos de calidad del aire establecidos en la normativa europea ${ }^{17}$.

El programa nacional deberá contener medidas aplicables a todos los sectores pertinentes tales como la agricultura, la generación de energía, la industria, el transporte por carretera, el transporte por vías navegables, la calefacción doméstica, la utilización de máquinas móviles no de carretera y el uso y fabricación de disolventes. Finalmente, en el capítulo IV se establecen diversos mecanismos de seguimiento de los objetivos del programa nacional ${ }^{18}$ y se revisa y actualiza la regulación del Sistema Español de Inventario y Proyecciones de Emisiones a la Atmósfera (SEI) y la obligación de elaborar los informes de inventarios y proyecciones de emisiones de los contaminantes atmosféricos y remitirlos a la Comisión Europea; $\mathrm{y}$, en el capítulo $\mathrm{V}$, se regula el régimen sancionador aplicable a los supuestos de incumplimiento de las prescripciones de este real decreto, que será el previsto en la Ley 34/2007, de 15 de noviembre. Además, la disposición adicional primera establece las consideraciones específicas para el uso de biocombustibles sólidos en calderas de uso no industrial y la disposición final segunda señala que este Real Decreto no afecta a las emisiones de contaminantes de los equipos y sistemas de armas necesarios para la protección de los intereses esenciales de la Defensa Nacional.

En materia de contaminación atmosférica, cabe señalar también la Orden $\mathrm{PCl} / 810 / 2018$, de 27 de julio, por la que se modifican los anexos II, XI y XVIII del Reglamento General de Vehículos, aprobado por Real Decreto 2822/1998, de 23 de diciembre ${ }^{19}$. El Plan Nacional de Calidad del Aire y Protección de la Atmósfera 2013-2016 (Plan AIRE), aprobado por el Acuerdo de Consejo de Ministros de 12 de abril de 2013, afirmaba que tanto las partículas como el

\footnotetext{
${ }^{17}$ Cabe señalar que la Directiva 2016/2284 del Parlamento Europeo y del Consejo, de 14 de diciembre excluye las Islas Canarias de su ámbito de aplicación por razones geográficas. Por este motivo, las emisiones de las Islas Canarias no se incluyen en el cumplimiento de los compromisos de reducción establecidos para España. En cambio, el programa nacional de control de la contaminación atmosférica contempla todo el territorio nacional.

${ }^{18}$ Tales como la constitución de una red territorial de medida de las emisiones y de los efectos de la contaminación atmosférica en los ecosistemas terrestres y acuáticos.

${ }^{19} \mathrm{Vid}$. BOE núm. 184, de 31 de julio de 2018.
} 
dióxido de nitrógeno tienen como principal fuente de emisión el tráfico de las grandes ciudades. El Plan Aire propuso, entre otras medidas, la clasificación de los vehículos en función de su potencial contaminador y, en particular, la identificación de los vehículos, a través de un distintivo ambiental adhesivo ubicado en el vehículo, con el fin de aplicar medidas ambientales relacionadas con la gestión del tráfico. El distintivo debe permitir su identificación visual e inmediata, tanto por medios humanos como automáticos, y facilitar la aplicación y el control efectivo de las medidas de tráfico establecidas. Por este motivo, el Organismo Autónomo Jefatura Central de Tráfico ha clasificado la totalidad del parque obrante en el Registro de Vehículos a través de criterios estrictamente ambientales, asignando a cada vehículo una categoría dentro de la escala ambiental creada: 0 emisiones, ECO, C, B y A. Correlativamente, se ha diseñado para las cuatro primeras categorías un distintivo ambiental, con la misma denominación que la categoría a la que pertenece, quedando la categoría A sin distintivo. En las resoluciones anuales por las que la Dirección General de Tráfico establece las medidas especiales de regulación del tráfico, se han incorporado los distintivos que identifican a los turismos según las emisiones; no obstante, por motivos de seguridad jurídica, ya que las citadas resoluciones tienen una vigencia limitada a un año y para ampliar su ámbito objetivo de aplicación, resulta imprescindible que la clasificación de los vehículos por criterios contaminantes y los distintivos pasen a regularse en el Reglamento General de Vehículos. Por ello, la citada Orden modifica el anexo II "Definiciones y categorías de los vehículos" del Reglamento General de Vehículos, para incorporar un nuevo apartado que contemple la clasificación de los vehículos en función de criterios contaminantes, con la denominación "E. Clasificación de vehículos por su potencial contaminante" y el anexo XI "Señales en los vehículos", para añadir una nueva señal relativa a los diferentes distintivos ambientales que se asignan a cada categoría de vehículo según su potencial contaminante, con la denominación de «V-25 Distintivo ambiental». Asimismo, la Orden incorpora la definición de vehículo de uso compartido en el apartado A. "Definiciones" del anexo II, e incluye el distintivo que lo identifica en el anexo XI "Señales en los vehículos" con la denominación de "V-26 Distintivo de uso compartido", consistente en un dispositivo adhesivo de ubicación interna o externa en el vehículo. Los vehículos de uso compartido 
están destinados al alquiler sin conductor y se dedican exclusivamente a su uso concatenado e intensivo por un número indeterminado de usuarios dentro de una zona de servicios delimitada. Los vehículos deben estar disponibles a través de una plataforma tecnológica para ser utilizados en cualquier momento por los clientes mediante el empleo de aplicaciones móviles. El vehículo de uso compartido supone un complemento de los sistemas de transporte público urbano, dotándole de una capilaridad añadida, introduciendo, además, una mayor eficiencia en el empleo del vehículo, reduciendo la congestión del tráfico, la ocupación de la vía pública y las emisiones contaminantes.

\subsection{En materia de hidrocarburos y gas natural}

Así como la contaminación atmosférica, otra prioridad a nivel español, europeo y mundial es la reducción de las emisiones de gases de efecto invernadero. A nivel europeo, el nuevo artículo 7 bis $^{20}$ de la Directiva 98/70/CE, de 13 de octubre de 1998, del Parlamento Europeo y del Consejo, relativa a la calidad de la gasolina y el gasóleo, establece métodos de cálculo de las emisiones de gases de efecto invernadero de los combustibles y la energía producidos a partir de fuentes no biológicas, así como los requisitos para la notificación y la elaboración de los informes exigidos al respecto. El citado artículo dispone que, como máximo el 31 de diciembre de 2020, deben haberse reducido las emisiones de gases de efecto invernadero durante el ciclo de vida por unidad de energía del carburante o por energía suministrados, hasta el 10 por ciento, del cual un 6 por ciento con carácter obligatorio y el 4 por ciento restante indicativo, en comparación con el nivel medio de emisiones de gases de efecto invernadero por unidad de energía de los combustibles fósiles utilizados en la Unión Europea en 2010. La Ley 34/1998, de 7 de octubre, del sector de hidrocarburos, que tiene por objeto renovar, integrar y homogeneizar la distinta normativa legal vigente en materia de hidrocarburos, profundiza en los mecanismos de información detallada que los agentes del mercado deben suministrar a las Administraciones competentes, para permitir la medición de

\footnotetext{
${ }^{20}$ Introducido por la Directiva 2009/30/CE del Parlamento Europeo y del Consejo, de 23 de abril de 2009, por la que se modifica la Directiva 98/70/CE en relación con las especificaciones de la gasolina, el diésel y el gasóleo, se introduce un mecanismo para controlar y reducir las emisiones de gases de efecto invernadero, se modifica la Directiva 1999/32/CE del Consejo en relación con las especificaciones del combustible utilizado por los buques de navegación interior y se deroga la Directiva 93/12/CEE.
} 
los resultados obtenidos y su contraste con los objetivos propuestos en materia de política energética.

El 27 de abril de este año fue aprobado el Real Decreto 235/2018, por el que se establecen métodos de cálculo y requisitos de información en relación con la intensidad de las emisiones de gases de efecto invernadero de los combustibles y la energía en el transporte; se modifica el Real Decreto 1597/2011, de 4 de noviembre, por el que se regulan los criterios de sostenibilidad de los biocarburantes y biolíquidos, el Sistema Nacional de Verificación de la Sostenibilidad y el doble valor de algunos biocarburantes a efectos de su cómputo; y se establece un objetivo indicativo de venta 0 consumo de biocarburantes avanzados ${ }^{21}$. El Real Decreto incorpora en el ordenamiento jurídico español la Directiva (UE) 2015/652 del Consejo, de 20 de abril de 2015, por la que se establecen métodos de cálculo y requisitos de notificación de conformidad con la citada Directiva 98/70/CE y parcialmente la Directiva (UE) 2015/1513 del Parlamento Europeo y del Consejo, de 9 de septiembre de 2015, por la que se modifican la Directiva 98/70/CE, relativa a la calidad de la gasolina y el gasóleo, y la Directiva 2009/28/CE, relativa al fomento del uso de energía procedente de fuentes renovables. El objeto del Real Decreto es: a) Establecer (en el art. 3 y en el anexo) un método de cálculo para determinar la intensidad de las emisiones de gases de efecto invernadero de los combustibles y la energía utilizados en el transporte y regular la remisión de información al respecto, según lo establecido en la Directiva (UE) 2015/652 del Consejo, de 20 de abril de 2015, por la que se establecen métodos de cálculo y requisitos de notificación de conformidad con la Directiva 98/70/CE del Parlamento Europeo y del Consejo, relativa a la calidad de la gasolina y el gasóleo. b) Establecer un objetivo indicativo de venta o consumo de biocarburantes avanzados. c) Adaptar los criterios de sostenibilidad de los biocarburantes y biolíquidos a lo establecido en la Directiva (UE) 2015/1513, del Parlamento Europeo y del Consejo, de 9 de septiembre de 2015, por la que se modifican la Directiva 98/70/CE, relativa a la calidad de la gasolina y el gasóleo, y la Directiva 2009/28/CE, relativa al fomento del uso de energía procedente de fuentes renovables. d) Completar el desarrollo del Sistema

${ }^{21}$ Vid. BOE núm. 105, de 1 de mayo de 2018. 
Nacional de Verificación de la Sostenibilidad de los biocarburantes y biolíquidos pasando a un sistema definitivo.

Respecto a este último punto, el Real Decreto modifica el Real Decreto 1597/2011, de 4 de noviembre, para culminar el actualmente vigente sistema transitorio de verificación de la sostenibilidad, pasando a un sistema definitivo, de forma que los sujetos obligados en el real decreto deberán sustituir, a partir del 1 de enero de 2019, la declaración responsable sobre el cumplimiento de la sostenibilidad de los biocarburantes, actualmente exigida, por un informe de verificación de la sostenibilidad realizado por una entidad de verificación de la sostenibilidad. De acuerdo con el artículo 4 del Real Decreto, antes del 31 de mayo de cada año, los sujetos previstos en el artículo 5, deberán remitir, a la Dirección General de Política Energética y Minas, información auditada sobre la intensidad de las emisiones de gases de efecto invernadero de los combustibles y la energía suministrados en el transporte recogidos en el artículo 6, durante el año natural anterior. Esta información se pondrá a disposición de la Oficina Española de Cambio Climático, del Ministerio de Agricultura y Pesca, Alimentación y Medio Ambiente. Cabe señalar, finalmente, que el Real Decreto objeto de análisis modifica numerosos artículos del Real Decreto 1597/2011, de 4 de noviembre, por el que se regulan los criterios de sostenibilidad de los biocarburantes y biolíquidos, el Sistema Nacional de Verificación de la Sostenibilidad y el doble valor de algunos biocarburantes a efectos de su cómputo, añade un nuevo anexo III, Parte A y Parte $B^{22}$ e incluye un nuevo anexo $\mathrm{IV}^{23}$.

En cuanto al sector del gas natural, se señala el Real Decreto 335/2018, de 25 de mayo, por el que se modifican diversos reales decretos que regulan el sector del gas natural. España es el País europeo con mayor número de plantas de regasificación y se encuentra a la cabeza de la Unión Europea en infraestructuras y capacidad de almacenamiento de gas natural licuado.

\footnotetext{
${ }^{22}$ Parte A "Emisiones estimadas provisionales de las materias primas de biocarburantes y biolíquidos, resultantes del cambio indirecto del uso de la tierra (g CO2 eq/MJ)"; Parte B "Biocarburantes y biolíquidos para los que las emisiones estimadas resultantes del cambio indirecto del uso de la tierra se consideran cero".

23 Anexo IV "Materias primas y carburantes de doble cómputo a efectos del cumplimiento de las obligaciones de venta o consumo de biocarburantes con fines de transporte y el objetivo establecido para la utilización de la energía procedente de fuentes renovables en todas las formas de transporte".
} 
Asimismo, por su situación geoestratégica, tiene un importante potencial para desarrollar el mercado de gas natural licuado orientado al suministro de este combustible en el transporte marítimo. Por ello, de acuerdo con el preámbulo del Real Decreto en objeto, se hace "necesario impulsar la utilización de las infraestructuras de gas natural licuado, flexibilizando los servicios de contratación de capacidad, tal y como establece el Real Decreto 984/2015, de 30 de octubre, por el que se regula el mercado organizado de gas y el acceso de terceros a las instalaciones del sistema de gas natural, donde se incluye un listado de servicios ofertados en las instalaciones incluidas en el régimen regulado de acceso de terceros". Flexibilizar los servicios de contratación de capacidad e incrementar la utilización de las infraestructuras, "aumentará los ingresos del sistema gasista, reforzando su sostenibilidad económica al mismo tiempo que contribuirá a alcanzar los objetivos perseguidos por la Directiva 2014/94/UE del Parlamento Europeo y del Consejo, de 22 de octubre de 2014, relativa a la implantación de una infraestructura para los combustibles alternativos (entre los que se encuentra el gas natural licuado o GNL) que fomenta su utilización frente a los derivados del petróleo, con el objetivo de limitar la contaminación y el cambio climático". Además del Real Decreto 984/2015, de 30 de octubre, por el que se regula el mercado organizado de gas y el acceso de terceros a las instalaciones del sistema de gas natural, el Real Decreto 335/2018, de 25 de mayo modifica el Real Decreto 949/2001, de 3 de agosto, para incluir, entre otras cosas, la definición de la estructura de los peajes aplicados a diversos servicios incluidos en el Real Decreto 984/2015, de 30 de octubre, (como son la entrada al Punto Virtual de Balance desde la red de distribución, la salida desde el Punto virtual de Balance a planta de regasificación o el almacenamiento en el Punto Virtual de Balance, que actualmente no cuentan con una estructura de peajes definida). Asimismo, modifica el citado Real Decreto para regular la baja del sistema retributivo de instalaciones de transporte, regasificación y almacenamiento básico en extensión de vida útil, circunstancia que no estaba prevista en la normativa vigente. Se trata de un procedimiento de carácter excepcional que deberá estar justificado en la baja utilización de las instalaciones y las previsiones de demanda que así lo encomienden para garantizar la sostenibilidad económica del sistema gasista y siempre que dichas instalaciones no sean necesarias 
para garantizar la seguridad del suministro energético. Se modifica también el Real Decreto 1434/2002, de 27 de diciembre, profundizando la regulación de los procedimientos de cierre de instalaciones, diferenciando entre el cierre temporal o definitivo de las mismas, ambos previa solicitud del titular e incluyendo un nuevo supuesto de hecho en el procedimiento de inhabilitación referido al incumplimiento de las obligaciones de pago de las empresas comercializadoras a terceros o al sistema gasista, y se regula el procedimiento de inhabilitación. Por último, se restablece la tramitación de las instalaciones afectadas por el apartado 2 de la disposición transitoria tercera del Real Decreto-ley 13/2012, de 30 de marzo, o sea los procedimientos de adjudicación y otorgamiento, incluyendo la autorización administrativa, la autorización del proyecto de ejecución o el acta de puesta en servicio, relativos a las plantas de regasificación que tuviesen aprobado el proyecto de ejecución antes de la entrada en vigor del Real Decreto.

Siempre en el ámbito de las políticas para necesaria reducción de las emisiones de gases efecto invernadero, señalamos el Real Decreto 1114/2018, de 7 de septiembre, por el que se regula la concesión directa de subvenciones para la implantación de instalaciones de refrigeración basadas en tecnologías alternativas a los gases fluorados de alto potencial de calentamiento atmosférico en establecimientos dedicados a la distribución comercial (Plan PIMA FRÍO) ${ }^{24}$. La Decisión 406/2009/CE del Parlamento Europeo y del Consejo, de 23 de abril de 2009, sobre el esfuerzo de los Estados miembros para reducir sus emisiones de gases de efecto invernadero a fin de cumplir los compromisos adquiridos por la Comunidad hasta 2020, señala que los esfuerzos para reducir las emisiones de gases de efecto invernadero (GEI) en los sectores afectados por el régimen comunitario de comercio de derechos de emisión no serán suficientes para hacer frente a los compromisos globales asumidos por la Unión Europea hasta el año 2020. Por ello, los Estados miembros deberán establecer políticas y medidas adicionales a fin de reducir las emisiones de los sectores denominados "difusos", comprometiéndose a disminuir conjuntamente sus emisiones en un $10 \%$ con respecto a 2005 en 2020. Entre los sectores "difusos", se encuentran las emisiones de gases

\footnotetext{
${ }^{24}$ Vid. BOE núm. 218, de 8 de septiembre de 2018.
} 
fluorados de efecto invernadero que en el año 2016 supusieron unas emisiones de aproximadamente 10 millones de toneladas de CO2-eq conforme al inventario nacional de emisiones de gases de efecto invernadero. Se estima que la cuarta parte de las emisiones se producen en el sector comercial producidas por fugas de los gases fluorados utilizados como refrigerantes en las instalaciones de refrigeración. En el sector de los gases fluorados, el Reglamento (UE) n. ${ }^{\circ}$ 517/2014 del Parlamento Europeo y del Consejo, de 16 de abril de 2014, en su anexo III, establece la prohibición de instalar a partir del 1 de enero de 2022 "centrales frigoríficas multicompresor compactas, para uso comercial, con una capacidad valorada igual o superior a $40 \mathrm{~kW}$, que contengan gases fluorados de efecto invernadero, o cuyo funcionamiento dependa de ellos, con un PCA igual o superior a 150, excepto en los circuitos refrigerantes primarios de los sistemas en cascada, en que pueden emplearse gases fluorados de efecto invernadero con un PCA inferior a 1 500". Puesto que las reconversiones supondrán un sobreesfuerzo inversor inicial en tecnologías aún incipientes en España, el objeto del Real Decreto 1114/2018 es la concesión de ayudas, por un total de 1,5 millones de euros, bajo ciertas condiciones de cumplimiento de las exigencias del reglamento europeo y de los requisitos de eficiencia en cuanto a consumo de energía.

\subsection{En materia de sector eléctrico}

El eléctrico es, sin duda, el sector donde se ha registrado la mayoría de actividad normativa en el periodo objeto de análisis, si bien se trata en gran medida de resoluciones y órdenes ministeriales. Además, en las novedades legislativas que analizaremos en seguida, se observa un primer cambio de ruta en las políticas eléctricas del nuevo Ministerio para la Transición Ecológica.

Analizando cronológicamente la normativa en materia eléctrica, en primer lugar, es necesario hacer referencia a la Circular 1/2018, de 18 de abril, de la Comisión Nacional de los Mercados y la Competencia, por la que se regula la gestión del sistema de garantía de origen de la electricidad procedente de fuentes de energía renovables y de cogeneración de alta eficiencia ${ }^{25}$. Esta Circular tiene por objeto establecer las normas de organización y

${ }^{25}$ Vid. BOE núm. 102, de 27 de abril de 2018. 
funcionamiento del Sistema de Garantía de Origen de la electricidad procedente de fuentes de energía renovables y de cogeneración de alta eficiencia. El Sistema de Garantía de Origen, del que la Comisión Nacional de los Mercados y la Competencia es responsable, es el instrumento a través del cual se asegura la publicidad y permanente gestión y actualización de la titularidad y control de las garantías de origen otorgadas a la electricidad generada a partir de fuentes de energía renovables y de cogeneración de alta eficiencia.

En segundo lugar, respeto a las reglas de funcionamiento de los mercados diario e intradiario de producción de energía eléctrica, cabe destacar que en mayo se aprobó la Resolución de 9 de mayo de 2018, de la Secretaría de Estado de Energía, por la que se aprueban las reglas de funcionamiento de los mercados diario e intradiario de producción de energía eléctrica ${ }^{26}$. Sin embargo, esta Resolución suscitó numerosas polémicas ya que establecía nuevas reglas para los citados mercados y algunas de ellas incompatibles con las aprobadas previamente por la Comisión Nacional de los Mercados y la Competencia (CNMC), que hasta entonces tenía atribuidas esas competencias. En efecto, la CNMC pocos días después presentó un recurso contencioso administrativo ante la Audiencia Nacional contra la Resolución, pidiéndole como medida cautelar la suspensión.

Un mes después, concretamente el 11 de junio, el nuevo Ministerio para la Transición Ecológica, ha modificado la citada Resolución a través de la Orden TEC/625/2018, de 11 de junio, por la que se avoca la competencia de la Secretaría de Estado de Energía y se modifica la Resolución de 9 de mayo de 2018, de la Secretaría de Estado de Energía, por la que se aprueban las reglas de funcionamiento de los mercados diario e intradiario de producción de energía eléctrica $^{27}$. La citada Orden, además de avocar la competencia de la Secretaría de Estado de Energía para poder dictar la Resolución, modifica dos aspectos concretos de la misma: deja sin efecto, por un lado, la regla $11^{\mathrm{a}}$ en lo

\footnotetext{
${ }^{26}$ Vid. BOE núm. 115 , de 11 de mayo de 2018.

${ }^{27}$ Vid. BOE núm. 142, de 12 de junio de 2018. Se tenga en cuenta también la Corrección de errores de la Orden TEC/625/2018, de 11 de junio, por la que se avoca la competencia de la Secretaría de Estado de Energía y se modifica la Resolución de 9 de mayo de 2018, de la Secretaría de Estado de Energía, por la que se aprueban las reglas de funcionamiento de los mercados diario e intradiario de producción de energía eléctrica, en BOE núm. 143, de 13 de junio de 2018.
} 
que se refiere a la obligación de presentar ofertas por cada unidad de venta, que no será de aplicación para el mercado intradiario continuo y, por el otro, la regla 46.1, donde se elimina el punto de unidad de oferta. Por último, la Orden establece que en el mercado intradiario, en el caso de contradicción o incompatibilidad entre las dos instituciones, se aplicará lo aprobado por la CNMC.

Además, siempre respecto al sector eléctrico, señalamos también el Real Decreto 1048/2018, de 24 de agosto, por el que se modifica el Real Decreto 1054/2014, de 12 de diciembre, por el que se regula el procedimiento de cesión de los derechos de cobro del déficit del sistema eléctrico del año 2013 y se desarrolla la metodología de cálculo del tipo de interés que devengarán los derechos de cobro de dicho déficit y, en su caso, de los desajustes temporales negativos posteriores ${ }^{28}$.

\section{OTRA NORMATIVA DE INTERÉS}

A las normas anteriormente reseñadas añadimos, en el período objeto de análisis, otras normas de interés en ámbitos sectoriales diversos.

Entre ellas, en materia de vehículos, señalamos la Orden PCl/824/2018, de 31 de julio, por la que se modifica el anexo I del Real Decreto 20/2017, de 20 de enero, sobre los vehículos al final de su vida útil ${ }^{29}$, que modifica el anexo I del Real Decreto 20/2017, de 20 de enero, sobre los vehículos al final de su vida útil para adaptarlo al nuevo anexo II de la Directiva 2000/53/CE del Parlamento Europeo y del Consejo, de 18 de septiembre de 2000, modificado por la Directiva (UE) 2017/2096 de la Comisión, de 15 de noviembre de 2017. En concreto el nuevo anexo de la Directiva incorpora como novedades la inclusión de una nueva exención a la prohibición de uso de plomo en baterías de sistemas de alta tensión que se utilizan para la propulsión de vehículos M1 y N1 y la modificación de la fecha de revisión de determinadas exenciones a 2019, 2021 o 2024. Recordamos que la Directiva 2000/53/CE del Parlamento Europeo y del Consejo, de 18 de septiembre de 2000, tiene como finalidad reducir las repercusiones negativas de los vehículos sobre el medio ambiente,

\footnotetext{
${ }^{28}$ Vid. BOE núm. 212, de 1 de septiembre de 2018.

${ }^{29}$ Vid. BOE núm. 186, de 2 de agosto de 2018.
} 
estableciendo para ello, no solamente normas sobre su correcta gestión ambiental, sino también medidas preventivas que deben tomarse en consideración desde la fase de su diseño y fabricación.

Respecto al tema de las cuencas hidrográficas, mencionamos la Orden TEC/921/2018, de 30 de agosto, por la que se definen las líneas que indican los límites cartográficos principales de los ámbitos territoriales de las Confederaciones Hidrográficas de acuerdo con lo establecido en el Real Decreto 650/1987, de 8 de mayo, por el que se definen los ámbitos territoriales de los organismos de cuenca y de los planes hidrológicos ${ }^{30}$. El objeto de la citada Orden es delimitar cartográficamente los ámbitos territoriales de las nueve confederaciones hidrográficas a todos los efectos previstos en el texto refundido de la Ley de Aguas, aprobado por Real Decreto Legislativo 1/2001, de 20 de julio, en el Real Decreto 650/1987, de 8 de mayo, por el que se definen los ámbitos territoriales de los organismos de cuenca y de los planes hidrológicos, y en el Real Decreto 125/2007, de 2 de febrero, por el que se fija el ámbito territorial de las demarcaciones hidrográficas.

${ }^{30}$ Vid. BOE núm. 220, de 11 de septiembre de 2018. 